\title{
Effects of Fatty Acid Quality and Quantity in the Japanese Diet on the Suppression of Lipid Accumulation
}

\author{
Yu Sakamoto, Kazushi Yamamoto, Yu Hatakeyama and Tsuyoshi Tsuduki* \\ Laboratory of Food and Biomolecular Science, Graduate School of Agriculture, Tohoku University (1-1 Tsutsumidori amamiyamachi, Aobaku, \\ Sendai 981-8555, JAPAN)
}

\begin{abstract}
Japan has been known as a healthy country since its life expectancy became among the highest in the world in the 1980s. The influence of the Japanese diet is one of the factors explaining Japan's high life expectancy. Our recent study that fed representative freeze-dried and powdered Japanese diets from 1960, 1975, 1990, and 2005 based on National Health and Nutrition Research to mice showed the 1975 Japanese diet exhibited the strongest visceral fat accumulation suppression and overall health benefits. However, it is unclear why. We investigated the effects of the fatty acid composition in Japanese diets on visceral fat accumulation in mice. ICR mice were fed diets replicating the fatty acid composition and macronutrient ratios of Japanese diets from 1960, 1975, 1990, and 2005 for four weeks. The 1975 diet suppressed visceral fat accumulation and adipocyte hypertrophy. DNA microarray analysis showed the 1975 diet suppressed Acyl-CoA synthetase and prostaglandin D2 synthase mRNA expressions in white adipose tissue. As the effects of the 1975 diet are likely due to differences in fatty acid intake and/or composition, we investigated test diets that replicated only the fatty acid composition of Japanese diets. There were no significant differences in visceral fat mass. Therefore, both the quality and quantity of fatty acids are involved in the anti-obesity effects of the 1975 Japanese diet.
\end{abstract}

Key words: mice, fatty acid composition, Japanese diet, Japanese food, obesity, macronutrient ratio

\section{INTRODUCTION}

Japan has been known as a healthy country since its life expectancy became among the highest in the world in the $1980 \mathrm{~s}^{1}$. The influence of the Japanese diet is one of the factors explaining Japan's high life expectancy. The Japanese diet is diverse and high in rice and traditional food such as fish, vegetables, and soy as well as meat, milk, oils, and fruits ${ }^{1)}$. In addition, lipid and protein contents differ from those of Western diets, because of high consumption of fresh seafood. Thus, the characteristic components of the Japanese diet have been widely studied. For example, Jelinek et al. report that replacing a portion of the lipid content in high-fat diet to fish oil decreases cholesterol and neutral fat levels in the livers of mice ${ }^{2)}$. Moreover, Nakagawa et al. report that green tea catechins enhance antioxidant activity in plasma in healthy men $^{3)}$. In meta-analysis of trials of blood lipids in humans, Anderson et al. found that replacing animal protein with soy protein decreases total cholesterol (TC), especially low-density lipoprotein cholesterol, and neutral fat levels ${ }^{4)}$. However, the impact of the Japanese diet on human health has scarcely been examined. In our previous study, we cooked modern Japanese and American foods and replicated, freeze-dried, powdered, and fed them to rats for three weeks ${ }^{1)}$; the results show lipid and peroxide lipid levels in the liver and plasma were lower in rats fed the Japanese diet than those fed the American diet. In particular, liver TC levels in rats fed the Japanese diet were approximately $70 \%$ of those in rats fed the American diet. Furthermore, DNA microarray analysis of gene expression levels in the liver showed the expressions of stress-response genes were lower while those of energy, glucose, and lipid metabolism-related genes were higher in rats fed the Japanese diet compared to those fed the American diet. This suggests the Japanese diet decreases stress, stimulates metabolism, and is less likely to cause obesity compared to the American diet. However, the contents of the Japanese diet have been greatly altered by Western influence in the last 50 years ${ }^{5}$. In particular,

\footnotetext{
*Correspondence to: Tsuyoshi Tsuduki, Laboratory of Food and Biomolecular Science, Graduate School of Agricultural Science, Tohoku University 1-1 Tsutsumidori-Amamiyamachi, Aoba-ku, Sendai 981-8555, JAPAN

E-mail: tsudukit@m.tohoku.ac.jp

Accepted October 6, 2015 (received for review June 23, 2015)

Journal of Oleo Science ISSN 1345-8957 print / ISSN 1347-3352 online

http://www.jstage.jst.go.jp/browse/jos/ http://mc.manusriptcentral.com/jjocs
} 


\section{Y. Sakamoto, K. Yamamoto and Y. Hatakeyama et al.}

rice consumption has halved, animal product consumption has quadrupled, and lipid consumption has tripled. Therefore, the Japanese diet may have been healthier in the past. However, it is unknown whether Japanese diets of any era are beneficial for maintaining health. A study that fed representative freeze-dried and powdered Japanese diets from 1960, 1975, 1990, and 2005 based on National Health and Nutrition Research to mice ${ }^{6,7)}$ showed the 1975 Japanese diet exhibited the strongest visceral fat accumulation suppression and overall health benefits. Furthermore, we investigated whether this effect of the 1975 Japanese diet depends on the macronutrient ratio, i.e., the ratio of proteins, lipids, and carbohydrates. To this end, purified diets that replicated the macronutrient ratio of the Japanese diet in each era were fed to ICR mice for four weeks. However, there were no differences in visceral fat quantity among groups; this suggests the effects of the 1975 Japanese diet do not solely depend on the differences in the macronutrient ratio. Therefore, in the present study, we focused on the quality of macronutrients, especially the fatty acid composition of lipids, in order to determine the influence of fatty acid composition in Japanese diets from various eras on visceral fat accumulation.

\section{MATERIALS \& METHODS}

\subsection{Test oil preparation}

The fatty acid compositions of Japanese diets from various eras were measured to prepare corresponding test oils (mimic oils here after). The total lipids from powdered Japanese diet, which were prepared as described previous$1 y^{6)}$, were extracted according to the procedure of Bligh \& Dyer $^{8)}$. In brief, $400 \mu \mathrm{L} 0.9 \% \mathrm{NaCl}$ solution(aq) containing $1 \mathrm{mM}$ EDTA was added to 50-100 mg of each sample, followed by the addition of $1000 \mu \mathrm{L} \mathrm{MeOH}$ and $500 \mu \mathrm{L} \mathrm{CHCl}_{3}$ containing butylated hydroxytoluene. The solution was then vortexed for $2 \mathrm{~min}$. And, $400 \mu \mathrm{L} 0.9 \% \mathrm{NaCl}$ solution (aq) and $500 \mu \mathrm{L} \mathrm{CHCl}_{3}$ were mixed, vortexed for $2 \mathrm{~min}$, and centrifuged for 5 min at $3000 \mathrm{rpm}$ at $4^{\circ} \mathrm{C}$ (Takara Tomy, Japan). The lower layer was transferred to another tube, and $1000 \mu \mathrm{L} \mathrm{CHCl}_{3}$ was added to the upper layer, vortexed for $2 \mathrm{~min}$, and centrifuged for $5 \mathrm{~min}$ at $3000 \mathrm{rpm}$ at $4^{\circ} \mathrm{C}$; this step was repeated three times. The total lipids were dried under a stream of nitrogen gas. To prepare the fatty acid methyl esters, the total lipids and a known amount of heptadecanoic acid (17:0) (Sigma, St. Louis, MO, USA) as an internal standard were methylated by the addition of $1000 \mu \mathrm{L} 5 \% \mathrm{HCl} / \mathrm{MeOH}$ for $30 \mathrm{~min}$ at $60^{\circ} \mathrm{C}$. Then, $3 \mathrm{~mL}$ hexane and $2 \mathrm{~mL} 2 \% \mathrm{KHCO}_{3}(\mathrm{aq})$ were added. The solution was vortexed for 2 min and centrifuged for 5 min at 3000 rpm at room temperature. The upper layer was transferred to another tube, $3 \mathrm{~mL}$ demineralized water was added, and the solution was vortexed for 2 min and centrifuged for 5 min at $1000 \mathrm{rpm}$ at room temperature. The upper layer was transferred to a centrifuge tube and dried by evaporator and a stream of nitrogen gas. The lipids were dissolved in $50 \mu \mathrm{L}$ hexane and subjected to gas chromatography (GC) (GC-2014, Shimadzu, Kyoto, Japan). Fatty acid composition was analyzed by GC using a flame ionization detector and a Supelco wax-10 fused silica capillary column $(60 \mathrm{~m} \times$ $0.32 \mathrm{~mm}, 0.25-\mu \mathrm{m}$ film thickness, Supelco, Bellefonte, PA, USA) as described previously ${ }^{9,10)}$. On the basis of the results, the mimic oils were prepared by mixing soybean oil, lard, palm oil, fish oil, and high oleic safflower oil. Preparation focused on the ratio of saturated, monounsaturated, and polyunsaturated fatty acids (S:M:P ratio) as well as the ratio of $\omega 6$ to $\omega 3$ polyunsaturated fatty acids $(\omega 6: \omega 3$ ratio). The mimic oils were prepared to match the proportions of the various Japanese diets.

\subsection{Test diet preparation}

The test diets were prepared as purified diets based on AIN-93G. The mimic oil-balanced diets were test diets that replicated the macronutrient ratio and fatty acid composition of the Japanese diets from different eras. Over time, the proportions of lipids and carbohydrates in the Japanese diet have increased and decreased, respectively ${ }^{7)}$ (Table 1); the mimic oil-balanced diets were prepared on the basis of these values. Meanwhile, the macronutrient ratios were replicated by milk casein (protein); mimic oils (lipid); and cornstarch, $\alpha$-cornstarch, and sucrose (carbohydrate) (Table 2). Moreover, the carbohydrate proportion was altered by changing only the amount of cornstarch.

On the other hand, the macronutrient ratios in the mimic oil diets were constant and based on the AIN-93G diet in all groups; the mimic oil diets only replicated fatty acid composition.

\subsection{Animals}

All animal procedures were performed in accordance with the Animal Experiment Guidelines of Tohoku University, and the animal protocol was approved by the Animal Use Committee at Tohoku University ${ }^{11)}$. Male ICR mice (four weeks old)were obtained from Japan Clea (Tokyo, Japan). The mice had access to their respective diet and distilled water ad libitum in a temperature- and humiditycontrolled room with a 12/12-h light/dark cycle. After accli-

Table 1 The macronutrient ratio of the Japanese food.

\begin{tabular}{lrrrr}
\hline & 1960 & 1975 & 1990 & 2005 \\
\cline { 2 - 5 } & \multicolumn{4}{c}{$(\%)$} \\
\hline Protein & 12.2 & 15.1 & 16.9 & 16.1 \\
Lipid & 9.8 & 17.1 & 21.4 & 25.8 \\
Carbohydrate & 78.0 & 67.8 & 61.7 & 58.1 \\
\hline
\end{tabular}


Table 2 The composition of the mimic oil-balanced diet.

\begin{tabular}{|c|c|c|c|c|c|c|}
\hline & & 1960 & 1975 & 1990 & 2005 & Normal \\
\hline Cornstarch & & 50.98 & 44.19 & 39.76 & 37.76 & 39.75 \\
\hline Milk casein powder & & 11.61 & 15.01 & 17.30 & 16.95 & 20.00 \\
\hline$\alpha$-cornstarch & & 13.20 & 13.20 & 13.20 & 13.20 & 13.20 \\
\hline Sucrose & & 10.00 & 10.00 & 10.00 & 10.00 & 10.00 \\
\hline Mimic oil & & 4.16 & 7.55 & 9.69 & 12.04 & 7.00 \\
\hline Cellulose powder & $(\mathrm{g} / 100 \mathrm{~g})$ & 5.00 & 5.00 & 5.00 & 5.00 & 5.00 \\
\hline Mineral mix (AIN-93G-MX) & & 3.50 & 3.50 & 3.50 & 3.50 & 3.50 \\
\hline Vitamin mix (AIN-93VX) & & 1.00 & 1.00 & 1.00 & 1.00 & 1.00 \\
\hline L-cystine & & 0.30 & 0.30 & 0.30 & 0.30 & 0.30 \\
\hline Choline bitartrate & & 0.25 & 0.25 & 0.25 & 0.25 & 0.25 \\
\hline Tertiary butylhydroquinone & & 0.0014 & 0.0014 & 0.0014 & 0.0014 & 0.0014 \\
\hline Energy & $(\mathrm{kcal} / 100 \mathrm{~g})$ & 381 & 398 & 408 & 420 & 395 \\
\hline
\end{tabular}

matization to CE-2 powdered diet from Japan Clea for one week, 48 mice were randomly divided into four groups (two cages with six mice per cage) each fed the 1960, 1975, 1990, or 2005 mimic oil-balanced diet (mb60, mb75, mb90, and mb05 groups, respectively) for four weeks. In addition, a normal group was fed AIN-93G powdered diet as a reference. At nine weeks of age, the mice were weighed and blood samples were collected by decapitation. The brain, heart, lungs, liver, pancreas, spleen, kidneys, and white adipose tissues were removed and weighed. Sera and organs were stored at $-80^{\circ} \mathrm{C}$ until use.

Moreover, the results of the test using the mimic oil diets were used to determine whether the effects of the diets were due to differences in the composition or amount of fatty acids. The 1960, 1975, 1990, or 2005 mimic oil diets or the reference diet were fed to the mice under the same conditions as mentioned above.

\subsection{Histological analysis of white adipose tissue}

Epididymal adipose tissue was fixed in 10\% formalin and embedded in paraffin ${ }^{12)}$. Vertical sections $(5 \mu \mathrm{m})$ were cut, mounted on glass slides, stained with hematoxylin \& eosin, and observed under a microscope (BZ-9000, Keyence, Osaka, Japan). The mean area of adipocytes in each group was calculated and compared.

\subsection{DNA microarray analysis}

For DNA microarray analysis, total RNA was isolated from epididymal adipose tissue using the RNeasy Lipid Tissue Mini Kit (QIAGEN, Valencia, CA, USA) ${ }^{13)}$ after elution with $30 \mu \mathrm{L}$ RNase-free water and stored at $-80^{\circ} \mathrm{C}$ until use. DNA microarray analysis was performed using the SuperPrint G3 Mouse GE $8 \times 60 \mathrm{~K}$ Microarray (Agilent Technology, Santa Clara, CA, USA) in the Takara Bio CDM Center(Mie, Japan).

\subsection{White adipose tissue, serum and liver biochemical analysis}

Biochemical analyses of epididymal adipose tissue, serum and liver samples were performed as described previously ${ }^{1,14)}$. The epididymal adipose tissue, serum and liver triacylglycerol (TG) were measured by using commercial enzyme kits (Wako Pure Chemical, Osaka, Japan) according to the manufacturer's instructions. The liver TC and Serum TC, phospholipid (PL) and glucose levels were measured by using commercial enzyme kits (Wako Pure Chemical, Osaka, Japan) according to the manufacturer's instructions. Serum insulin levels were determined by ELISA (Morinaga Institute of Biological Science, Kanagawa, Japan) according to the manufacturer's instructions. The liver PL levels were measured according to the procedure of Rouser $e t a l .{ }^{15)}$.

\subsection{GC analysis of total lipid in white adipose tissue, se- rum and liver}

The total lipids from epididymal adipose tissue, serum and liver were extracted according to the procedure of Bligh \& Dyer ${ }^{8)} .50 \mathrm{mg}$ of epididymal adipose tissue, $400 \mu \mathrm{L}$ of serum or $150 \mathrm{mg}$ of liver were used and performed in the same method as described above (2.1. Test oil preparation). The amount of serum samples were small, so they were pooled for each group. The methyl esterified lipids were dissolved in $1000 \mu \mathrm{L}$ hexane and subjected to GC (GC-4000 Plus, GL Sciences, Tokyo, Japan). Fatty acid composition was analyzed by GC using a flame ionization detector and a Supelco wax-10 fused silica capillary column ( $60 \mathrm{~m} \times 0.25 \mathrm{~mm}, 0.25-\mu \mathrm{m}$ film thickness, Supelco, Bellefonte, PA, USA).

\subsection{Statistical analysis}

Data are shown mean \pm SE. Data were analyzed by one-way ANOVA followed by Tukey's multiple comparison 
test for comparisons among four groups. The level of significance was set at $p<0.05$. The reference group was not included in the analysis. The stepwise multiple regression analysis was performed to explore determinants of total white adipose tissue weight. The fatty acids (14:0, 16:0, 16:1 n-7, 18:0, 18:1 n-9, 18:1 n-7, 18:2 n-6, 18:3 n-3, 20:1 n-9, 20:3 n-3, 20:4 n-6, 20:5 n-3 and 22:6 n-3) in epididymal adipose tissue were included as predictors in the original model. The level of significance was set at $p<0.05$ for regression analysis.

\section{RESULTS}

\subsection{Composition of the mimic oil-balanced diets}

Preparation of the mimic oils focused on the fatty acid composition, especially the S:M:P and $\omega 6: \omega 3$ ratios. The lipids extracted from the Japanese diets were analyzed by GC, and respective mimic oils were prepared by using five kinds of oils (Table 3). GC analysis of the mimic oils demonstrated they replicated the fatty acid composition of the Japanese diets. The mimic oil-balanced diets, which replicated the macronutrient ratio and fatty acid composition of the Japanese diets by altering the amounts of purified diet and mimic oil, were subsequently prepared (Table 2). In addition, the fatty acid contents of test diets were shown in Supplemental table 1 and 2 . As a result, the amount of increase in EPA and DHA (increased $0.09 \mathrm{~g}$ from1975 year to 2005 year) were lower than that in saturated fatty acid (increased $1.05 \mathrm{~g}$ from1975 year to 2005 year).

\subsection{Effects of mimic oil-balanced diets on growth param- eters}

There were no significant differences in the final body weight and body weight gain among the four groups (Table 4). Although food intake was significantly higher in the mb60 group than the others, there was no significant difference in energy intake among groups. The mesenteric and perirenal adipose tissue weights were significantly lower in the mb75 group than the mb90 and mb05 groups. The epididymal adipose tissue weight was significantly lower in the mb75 group than the mb90 group. In addition, the total adipose tissue weight was significantly lower in the mb75 group than the other groups. There were no significant differences in brain, heart, lung, liver, pancreas, spleen, or kidney weights among groups. Thus, the results suggest the 1975 mimic oil-balanced diet suppressed lipid accumulation in epididymal adipose tissue.

\subsection{Histological analysis of white adipose tissue of mice fed mimic oil-balanced diets}

The decreased adipose tissue weight suggests the 1975 mimic oil-balanced diet suppressed obesity. Thus, the epididymal adipose tissues were stained with hematoxylin \& eosin and subjected to histological analysis. Adipocytes were smaller in mb75 group than the other groups (Fig. 1). In addition, the area of adipocytes in each group was calculated. With the normal group set as 1.00 , the adipocyte areas in the mb60, mb75, mb90, and mb05 groups were $0.98 \pm 0.06,0.72 \pm 0.05,0.98 \pm 0.08$, and $1.19 \pm 0.13$, respectively; the adipocyte area was significantly smaller in the mb75 group than the mb05 group $(p=0.009)$. This result suggests adipocyte hypertrophy in white adipose tissue was suppressed by intake of the 1975 mimic oil-balanced diet.

Table 3 The fatty acid composition of mimic oil.

\begin{tabular}{lcccc}
\hline & 1960 & 1975 & 1990 & 2005 \\
\hline Preparation of mimic oil & & & $(\%)$ & \\
Soybean oil & 40.3 & 31.8 & 26.0 & 25.1 \\
Lard & 26.1 & 37.1 & 56.0 & 41.3 \\
Palm oil & 16.3 & 13.6 & 9.0 & 15.5 \\
Fish oil & 10.7 & 11.4 & 8.0 & 12.3 \\
High oleic safflower oil & 6.5 & 6.2 & 1.1 & 5.8 \\
\hline S:M:P ratio & & & & \\
Japanese food & $1.0: 1.3: 1.1$ & $1.0: 1.3: 0.9$ & $1.0: 1.2: 0.7$ & $1.0: 1.2: 0.7$ \\
Mimic oil & $1.0: 1.3: 1.1$ & $1.0: 1.3: 0.9$ & $1.0: 1.2: 0.7$ & $1.0: 1.3: 0.8$ \\
\hline$\omega 6: \omega 3$ ratio & & & & \\
Japanese food & 5.0 & 4.4 & 5.0 & 4.0 \\
Mimic oil & 5.0 & 4.5 & 5.0 & 4.0 \\
\hline
\end{tabular}

$\mathrm{S}$, saturated fatty acid; $\mathrm{M}$, monounsaturated fatty acid; $\mathrm{P}$, polyunsaturated fatty acid. 
Table 4 Body weight, food intake, energy intake and tissue weight in mice fed mimic oil-balanced diet.

\begin{tabular}{lcccc:c}
\hline & $\mathrm{mb} 60$ & $\mathrm{mb} 75$ & $\mathrm{mb} 90$ & $\mathrm{mb} 05$ & Normal \\
\hline Final body weight $(\mathrm{g})$ & $40.9 \pm 0.6$ & $41.2 \pm 0.8$ & $42.3 \pm 0.7$ & $43.0 \pm 1.6$ & $40.5 \pm 0.6$ \\
Body weight gain (g) & $9.20 \pm 0.27$ & $9.41 \pm 0.49$ & $10.5 \pm 0.4$ & $10.9 \pm 1.2$ & $8.67 \pm 0.20$ \\
Food intake (g/day) & $4.91 \pm 0.16^{\mathrm{b}}$ & $4.65 \pm 0.13^{\mathrm{a}}$ & $4.51 \pm 0.15^{\mathrm{a}}$ & $4.53 \pm 0.18^{\mathrm{a}}$ & $4.76 \pm 0.18$ \\
Energy intake (kcal/day) & $18.7 \pm 0.6$ & $18.5 \pm 0.5$ & $18.4 \pm 0.6$ & $19.0 \pm 0.8$ & $18.8 \pm 0.7$ \\
Tissue weight & & & $(\mathrm{g} / 100 \mathrm{~g} \mathrm{~B} . \mathrm{W})$. & & \\
$\quad$ Brain & $1.28 \pm 0.02$ & $1.24 \pm 0.02$ & $1.24 \pm 0.02$ & $1.20 \pm 0.05$ & $1.26 \pm 0.02$ \\
Heart & $0.47 \pm 0.01$ & $0.49 \pm 0.02$ & $0.46 \pm 0.01$ & $0.45 \pm 0.01$ & $0.45 \pm 0.01$ \\
Lung & $1.19 \pm 0.13$ & $1.08 \pm 0.12$ & $1.05 \pm 0.10$ & $0.89 \pm 0.08$ & $1.13 \pm 0.15$ \\
Liver & $3.91 \pm 0.08$ & $3.99 \pm 0.05$ & $3.85 \pm 0.04$ & $3.89 \pm 0.08$ & $4.01 \pm 0.08$ \\
Pancreas & $0.82 \pm 0.03$ & $0.84 \pm 0.02$ & $0.87 \pm 0.02$ & $0.80 \pm 0.02$ & $0.81 \pm 0.02$ \\
Spleen & $0.29 \pm 0.01$ & $0.32 \pm 0.01$ & $0.27 \pm 0.01$ & $0.29 \pm 0.01$ & $0.28 \pm 0.01$ \\
Kidney & $1.50 \pm 0.03$ & $1.59 \pm 0.07$ & $1.59 \pm 0.06$ & $1.69 \pm 0.05$ & $1.69 \pm 0.04$ \\
White adipose tissue & & & & & \\
$\quad$ Mesenteric & $0.88 \pm 0.06^{\mathrm{ab}}$ & $0.64 \pm 0.08^{\mathrm{a}}$ & $1.05 \pm 0.10^{\mathrm{b}}$ & $1.04 \pm 0.11^{\mathrm{b}}$ & $0.84 \pm 0.08$ \\
$\quad$ Perinephric & $1.15 \pm 0.12^{\mathrm{ab}}$ & $0.68 \pm 0.09^{\mathrm{a}}$ & $1.22 \pm 0.13^{\mathrm{b}}$ & $1.43 \pm 0.17^{\mathrm{b}}$ & $1.24 \pm 0.14$ \\
$\quad$ Epididymal & $2.25 \pm 0.11^{\mathrm{ab}}$ & $1.59 \pm 0.21^{\mathrm{a}}$ & $2.50 \pm 0.23^{\mathrm{b}}$ & $2.33 \pm 0.23^{\mathrm{ab}}$ & $2.17 \pm 0.18$ \\
$\quad$ Total & $4.39 \pm 0.17^{\mathrm{b}}$ & $2.91 \pm 0.33^{\mathrm{a}}$ & $4.76 \pm 0.42^{\mathrm{b}}$ & $4.80 \pm 0.45^{\mathrm{b}}$ & $4.26 \pm 0.31$ \\
\hline
\end{tabular}

Data are shown as mean $\pm \mathrm{SE}, \mathrm{n}=12$. Different superscript letters indicate significant differences $\left({ }^{\mathrm{a}}, \mathrm{b} p<0.05\right)$. The mb60, mb75, mb90, and mb05 groups were fed the 1960, 1975, 1990, and 2005 mimic oil-balanced diets, respectively, and the normal group was fed the AIN-93G powdered diet.

\subsection{DNA microarray analysis of white adipose tissue of mice fed mimic oil-balanced diets}

Because the lipid accumulation and hypertrophy of adipocytes in epididymal adipose tissue were suppressed by intake of the 1975 mimic oil-balanced diet, the differences in gene expression between the mb75 group and other three groups were evaluated by DNA microarray. A difference was considered to exist if the gene expression ratio of the mb75 group was more than 2 compared to that of the other three groups. All of the genes that expression ratio of the mb75 group was more than 2 compared to that of the other three groups were shown in Supplemental table 3. Genes whose expressions differed between groups were classified by function(Table 5); genes that did not have a metabolic-related function were classified as others. The expressions of 10 metabolism-related genes were significantly lower in the mb75 group than the other groups (Table 6). Carbohydrate metabolism-related genes included calmodulin-like protein 3 (Calml3), which is involved in glycogenesis suppression, solute carrier family 2 member 5 (Slc2a5), which is involved in fructose transport, NME/ NM23 family member 5 (Nme5), which converts nucleotide diphosphate to the triphosphate form, and hepatic nuclear factor 4, alpha (Hnf $4 a$ ), which promotes G6Pase transcription. Lipid metabolism-related genes included acyl-CoA synthetase bubblegum family member 1 (Acsbg1), which synthesizes acyl-CoA, arylacetamide deacetylase (Aadac), which decomposes triacylglycerol, and prostaglandin D2 synthase (Ptgds), which synthesizes prostaglandin D2. Amino acid metabolism-related genes included d-amino acid oxidase $(D a o)$, which converts d-amino acids to imino acids, pipecolic acid oxidase (Pipox), which synthesizes glycine from sarcosine, and butyrobetaine 2-oxoglutarate dioxygenase (Bbox1), which decomposes lysine. These results suggest the 1975 mimic oil-balanced diet suppressed obesity by decreasing the expression levels of the above mentioned metabolism-related genes.

\subsection{Effects of mimic oil-balanced diets on white adipose tissue, serum and liver biochemical parameters}

There were no significant differences in epididymal adipose tissue TG level, in serum TG, TC, PL glucose, or insulin levels and in liver TG, TC, PL levels among the four groups (Table 7, 8, Supplemental table 4).

\subsection{Effects of mimic oil-balanced diets on the fatty acid} composition in white adipose tissue, serum and liver

The fatty acid composition in epididymal adipose tissue, serum and liver were analyzed (Table 9, Supplemental table 5,6$)$. In the epididymal adipose tissue, 16:1 n-7 was 

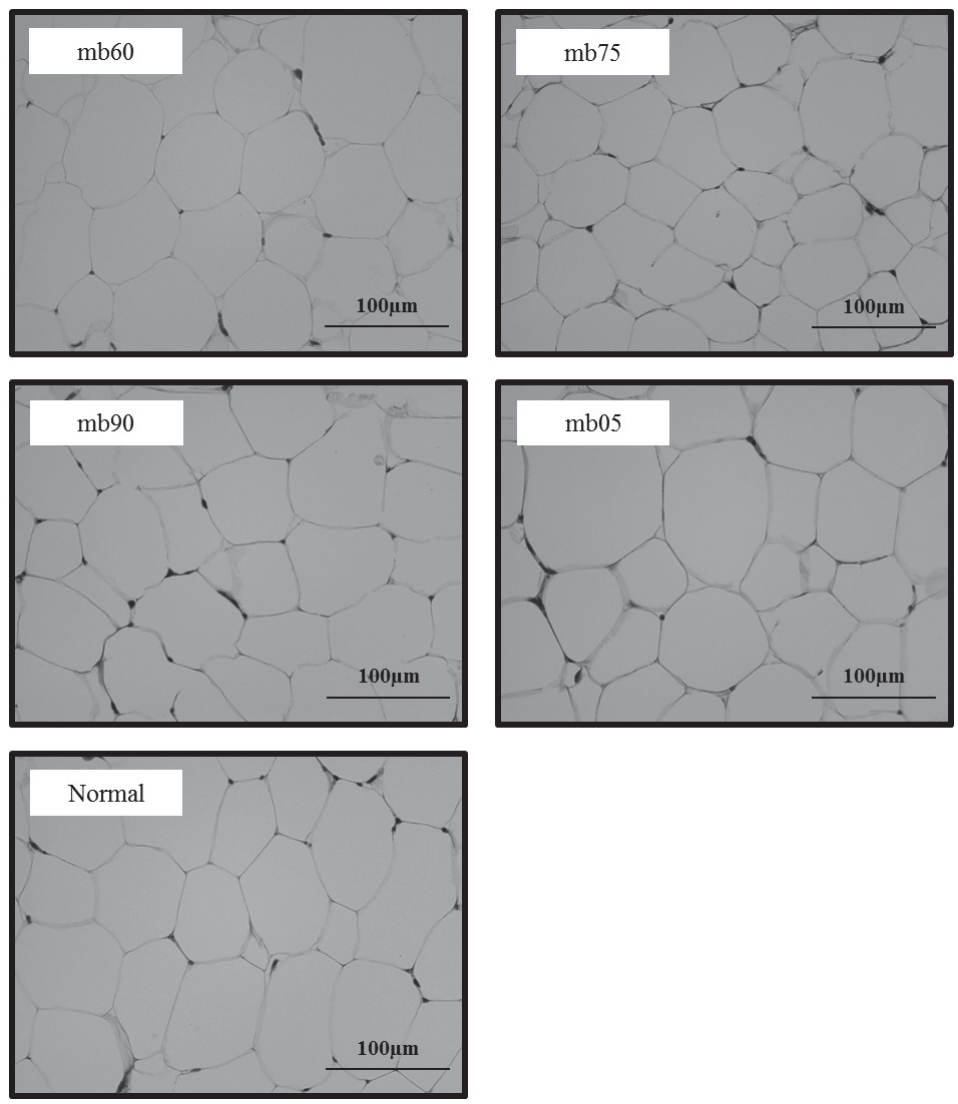

Fig. 1 Effects of the mimic oil-balanced diets on white adipose tissue in mice.

Epididymal adipose tissue sections from representative mice of each group (hematoxylin \& eosin, scale bar $=$ $100 \mu \mathrm{m})$. The mb60, mb75, mb90, and mb05 groups were fed the 1960, 1975, 1990, and 2005 mimic oilbalanced diets, respectively, and the normal group was fed the AIN-93G powdered diet.

Table 5 Functional classification of genes observed a difference in the expression ratio.

\begin{tabular}{lcc}
\hline \multirow{2}{*}{ Gene function } & \multicolumn{2}{c}{ Expression ratio } \\
\cline { 2 - 3 } & Increase $\uparrow$ & Decrease $\downarrow$ \\
\hline Carbohydrate metabolism & 0 & 4 \\
Lipid metabolism & 0 & 3 \\
Amino acid metabolism & 0 & 3 \\
The other & 3 & 69 \\
\hline Total & 3 & 79
\end{tabular}

Genes observed the differences in epididymal adipose tissue in the expression ratio were classified by function. Genes which did not have the metabolic-related function were classified as other.

significantly lower in the mb75 and mb05 groups than the mb60 group. 18:0 was significantly lower in the mb60 group than the mb90 and mb05 groups. 18:1 n-7 was significantly lower in the mb75, mb90 and mb05 groups than the mb60 group. 20:4 n-6 was significantly lower in the mb75 group than the mb60 group. In the liver, 16:1 n-7 was significantly lower in the mb75 group than the mb60 group and higher than the mb05 group. 18:0 was significantly lower in the mb60 group than the mb05 group. 18:1 n-7 was significantly lower in the mb75, mb90 and mb05 groups than the mb60 group. 18:2 n-6 was significantly higher in the mb75 group than the mb60 group. 20:5 n-3 was significantly lower in the mb60, mb75 and mb90 groups than the mb05 group. 22:6 n-3 was significantly lower in the mb60 group than the mb75, mb90 and mb05 groups.

\subsection{Multiple regression analysis}

The best predictor of total white adipose tissue weight variation differing significantly, demonstrated by stepwise regression analysis of fatty acid composition, were shown in Table 10. 14:0 was an independent positive predictor of total white adipose tissue weights $(p<0.01)$. 18:0 was an independent positive predictor of total white adipose tissue weights $(p<0.05)$. 18:2 n-6 was an independent negative predictor of total white adipose tissue weights $(p<0.01)$. 
Table 6 Carbohydrate metabolism, lipid metabolism and amino acid metabolism related gene.

\begin{tabular}{lllccc}
\hline \multirow{2}{*}{ Genebank ID } & Gene Symbol & \multicolumn{3}{c}{ Expression ratio (vs mb60) } & \multirow{2}{*}{ Pathway } \\
\cline { 3 - 4 } & & mb75 & mb90 & mb05 & \\
\hline NM_027416 & Calml3 & -7.72 & -0.74 & 0.94 & \\
NM_008261 & Hnf4a & -2.97 & -0.86 & 0.79 & Carbohydrate \\
NM_080637 & Nme5 & -3.18 & -0.51 & 0.85 & metabolism \\
NM_019741 & Slc2a5 & -3.68 & -0.92 & 1.66 & \\
\hline NM_023383 & Aadac & -3.28 & -0.46 & 1.10 & Lipid \\
NM_053178 & Acsbg1 & -4.58 & -1.16 & 0.75 & metabolism \\
NM_008963 & Ptgds & -3.18 & -0.60 & 0.66 & \\
\hline NM_130452 & Bbox1 & -3.43 & -0.54 & 0.80 & Amino acid \\
NM_001286396 & Dao & -7.58 & -1.23 & 0.74 & metabolism \\
NM_008952 & Pipox & -3.47 & -0.81 & 0.95 & \\
\hline
\end{tabular}

The bottom was expressed as 2 in logarithm. It was determined that if gene expression ratio of mb75 group was more than 2 times compared to the other three groups in epididymal adipose tissue, the differences were observed. The mb60, mb75, mb90, and mb05 groups were fed the 1960, 1975, 1990, and 2005 mimic oil-balanced diets, respectively. Aadac, arylacetamide deacetylase; Acsbg1, acyl-CoA synthetase bubblegum family member 1; Bboxl, butyrobetaine 2-oxoglutarate dioxygenase; Calml3, calmodulin-like protein 3; Dao, D-amino acid oxidase; Hnf4a, hepatic nuclear factor 4, alpha; Nme5, NME/NM23 family member 5; Pipox, pipecolic acid oxidase; Ptgds, prostaglandin D2 synthase; Slc2a 5, solute carrier family 2 member 5.

Table 7 Biochemical parameters in serum in mice fed mimic oil-balanced diet.

\begin{tabular}{lccccc:c}
\hline & & $\mathrm{mb60}$ & $\mathrm{mb75}$ & $\mathrm{mb} 0$ & $\mathrm{mb05}$ & Normal \\
\hline TG & $(\mathrm{mmol} / \mathrm{L})$ & $1.09 \pm 0.07$ & $0.96 \pm 0.07$ & $0.93 \pm 0.05$ & $0.92 \pm 0.08$ & $1.58 \pm 0.07$ \\
$\mathrm{TC}$ & $(\mathrm{mmol} / \mathrm{L})$ & $2.44 \pm 0.16$ & $2.25 \pm 0.14$ & $2.28 \pm 0.09$ & $2.36 \pm 0.13$ & $2.68 \pm 0.17$ \\
$\mathrm{PL}$ & $(\mathrm{mmol} / \mathrm{L})$ & $2.09 \pm 0.13$ & $1.90 \pm 0.10$ & $1.97 \pm 0.07$ & $1.90 \pm 0.06$ & $2.29 \pm 0.11$ \\
& & & & & & \\
Glucose & $(\mathrm{mmol} / \mathrm{L})$ & $4.64 \pm 0.28$ & $4.41 \pm 0.30$ & $4.32 \pm 0.32$ & $5.20 \pm 0.30$ & $4.51 \pm 0.41$ \\
Insulin & $(\mathrm{pmol} / \mathrm{L})$ & $34.5 \pm 7.0$ & $30.9 \pm 5.7$ & $37.9 \pm 7.5$ & $46.9 \pm 7.7$ & $35.3 \pm 6.0$ \\
\hline
\end{tabular}

Data are shown as mean $\pm \mathrm{SE}, \mathrm{n}=12$. Different superscript letters indicate significant differences ( ${ }^{\mathrm{a}, \mathrm{b}} p<0.05$ ). The mb60, mb75, mb90, and mb05 groups were fed the 1960, 1975, 1990, and 2005 mimic oil-balanced diets, respectively, and the normal group was fed the AIN-93G powdered diet. TC, total cholesterol; TG, triacylglycerol; PL, phospholipid.

Table 8 Biochemical parameters in epididymal adipose tissue in mice fed mimic oil-balanced diet.

\begin{tabular}{cccccc|c}
\hline & & $\mathrm{mb60}$ & $\mathrm{mb75}$ & $\mathrm{mb90}$ & $\mathrm{mb05}$ & Normal \\
\hline TG & $(\mathrm{mmol} / \mathrm{g})$ & $0.364 \pm 0.017$ & $0.365 \pm 0.018$ & $0.344 \pm 0.021$ & $0.391 \pm 0.012$ & $0.353 \pm 0.018$ \\
\hline
\end{tabular}

Data are shown as mean $\pm \mathrm{SE}, \mathrm{n}=8-12$. Different superscript letters indicate significant differences $(p$ $<0.05$ ). The mb60, mb75, mb90, and mb05 groups were fed the 1960, 1975, 1990, and 2005 mimic oilbalanced diets, respectively, and the normal group was fed the AIN-93G powdered diet. TG, triacylglycerol. 
Table 9 The fatty acid composition in epididymal adipose tissue in mice fed mimic oil-balanced diet.

\begin{tabular}{lcccc:c}
\hline & $\mathrm{mb} 60$ & $\mathrm{mb} 75$ & $\mathrm{mb} 90$ & $\mathrm{mb} 05$ & Normal \\
\cline { 2 - 6 } & \multicolumn{3}{c}{$(\%)$} \\
\hline $14: 0$ & $1.3 \pm 0.0$ & $1.3 \pm 0.0$ & $1.4 \pm 0.0$ & $1.4 \pm 0.0$ & $0.9 \pm 0.0$ \\
$16: 0$ & $24.8 \pm 0.4$ & $24.7 \pm 0.4$ & $25.1 \pm 0.5$ & $25.3 \pm 0.5$ & $19.2 \pm 0.4$ \\
$16: 1 \mathrm{n}-7$ & $6.4 \pm 0.4^{\mathrm{b}}$ & $4.7 \pm 0.3^{\mathrm{a}}$ & $5.0 \pm 0.5^{\mathrm{ab}}$ & $4.1 \pm 0.2^{\mathrm{a}}$ & $4.3 \pm 0.3$ \\
$18: 0$ & $2.4 \pm 0.1^{\mathrm{a}}$ & $3.1 \pm 0.1^{\mathrm{ab}}$ & $3.4 \pm 0.1^{\mathrm{b}}$ & $3.5 \pm 0.1^{\mathrm{b}}$ & $1.7 \pm 0.2$ \\
$18: 1 \mathrm{n}-9$ & $38.9 \pm 0.8$ & $39.0 \pm 0.7$ & $39.8 \pm 0.4$ & $40.1 \pm 0.4$ & $25.6 \pm 3.2$ \\
$18: 1 \mathrm{n}-7$ & $3.0 \pm 0.2^{\mathrm{b}}$ & $2.6 \pm 0.1^{\mathrm{a}}$ & $2.4 \pm 0.1^{\mathrm{a}}$ & $2.2 \pm 0.0^{\mathrm{a}}$ & $6.7 \pm 2.9$ \\
$18: 2 \mathrm{n}-6$ & $20.3 \pm 0.7$ & $21.9 \pm 0.6$ & $20.1 \pm 0.4$ & $20.7 \pm 0.6$ & $37.7 \pm 0.8$ \\
$18: 3 \mathrm{n}-6$ & n.d. & n.d. & n.d. & n.d. & n.d. \\
$18: 3 \mathrm{n}-3$ & $1.3 \pm 0.1$ & $1.4 \pm 0.1$ & $1.3 \pm 0.0$ & $1.3 \pm 0.0$ & $2.9 \pm 0.2$ \\
$20: 1 \mathrm{n}-9$ & $0.6 \pm 0.0$ & $0.6 \pm 0.0$ & $0.5 \pm 0.0$ & $0.5 \pm 0.0$ & $0.4 \pm 0.0$ \\
$20: 3 \mathrm{n}-3$ & $0.1 \pm 0.0$ & $0.1 \pm 0.0$ & $0.1 \pm 0.0$ & $0.1 \pm 0.0$ & $0.2 \pm 0.0$ \\
$20: 4 \mathrm{n}-6$ & $0.4 \pm 0.1^{\mathrm{b}}$ & $0.2 \pm 0.0^{\mathrm{a}}$ & $0.3 \pm 0.0^{\mathrm{ab}}$ & $0.2 \pm 0.0^{\mathrm{ab}}$ & $0.4 \pm 0.0$ \\
$20: 5 \mathrm{n}-3$ & $0.1 \pm 0.0$ & $0.1 \pm 0.0$ & $0.1 \pm 0.0$ & $0.1 \pm 0.0$ & n.d. \\
$22: 6 \mathrm{n}-3$ & $0.4 \pm 0.1$ & $0.4 \pm 0.1$ & $0.5 \pm 0.1$ & $0.4 \pm 0.1$ & $0.1 \pm 0.0$ \\
\hline Da & &
\end{tabular}

Data are shown as mean $\pm \mathrm{SE}, \mathrm{n}=11-12$. Different superscript letters indicate significant differences $\left({ }^{\mathrm{a}, \mathrm{b}} p<0.05\right)$. The mb60, mb75, mb90, and mb05 groups were fed the 1960, 1975, 1990, and 2005 mimic oil-balanced diets, respectively, and the normal group was fed the AIN-93G powdered diet. n.d., not detected.

Table 10 Best predictors of variation in total white adipose tissue weight in a stepwise regression analysis.

\begin{tabular}{llccc}
\hline & Predictor & beta coefficient & $P$ & Adjusted $^{2}$ \\
\hline Total white adipose tissue weight & $14: 0$ & 0.4048 & 0.0009 & \\
& $18: 0$ & 0.2990 & 0.0175 & 0.4370 \\
& $18: 2 \mathrm{n}-6$ & -0.5068 & 0.0001 & \\
\hline
\end{tabular}

$\mathrm{n}=11-12$.

\subsection{Effects of mimic oil diets on growth parameters}

In order to elucidate the effects of the 1975 mimic oilbalanced diet with respect to differences in the amounts of fatty acids or their composition, the experiment was performed by using the mimic oil diet that replicated only fatty acid composition. There were no significant differences in final body weight and body weight gain among the four groups (Table 11). Food intake was significantly lower in the m90 group than the m60 and m05 groups. There were no significant differences in the mesenteric, perirenal, and epididymal adipose tissue weights among groups. Moreover, there were no significant differences in the brain, heart, lung, liver, pancreas, spleen, or kidney weights. These results suggest the suppression of lipid accumulation by intake of the 1975 mimic oil-balanced diet does not depend solely on its fatty acid composition.

\subsection{Histological analysis of white adipose tissue in mice fed mimic oil diets}

Epididymal adipose tissue sections were stained with hematoxylin \& eosin and subjected to histological analysis. There was no significant difference among the four groups with respect to adipocyte size(Fig. 2): when the adipocyte size of the normal group was set at 1.00, the adipocyte sizes of the m60, m75, m90, and m05 groups were $1.12 \pm$ $0.05,1.11 \pm 0.04,1.15 \pm 0.07$, and $1.08 \pm 0.03$, respectively. Furthermore, there was no significant difference among the groups with respect to adipocyte area. These results further suggest the suppression of adipocyte hypertrophy by intake of the 1975 mimic oil-balanced diet does not depend solely on its fatty acid composition. 
Table 11 Body weight, food intake and tissue weight in mice fed mimic oil diet.

\begin{tabular}{lcccc|c}
\hline & $\mathrm{m} 60$ & $\mathrm{~m} 75$ & $\mathrm{~m} 90$ & $\mathrm{~m} 05$ & Normal \\
\hline Final body weight $(\mathrm{g})$ & $42.7 \pm 0.8$ & $42.8 \pm 1.2$ & $41.0 \pm 0.7$ & $42.4 \pm 0.9$ & $42.9 \pm 1.1$ \\
Body weight gain $(\mathrm{g})$ & $10.7 \pm 0.7$ & $10.8 \pm 0.8$ & $8.98 \pm 0.52$ & $10.3 \pm 0.6$ & $10.9 \pm 0.8$ \\
Food intake (g/day) & $4.61 \pm 0.36^{\mathrm{b}}$ & $4.58 \pm 0.23^{\mathrm{ab}}$ & $4.39 \pm 0.40^{\mathrm{a}}$ & $4.75 \pm 0.29^{\mathrm{b}}$ & $4.87 \pm 0.28$ \\
Tissue weight & & & $(\mathrm{g} / 100 \mathrm{~g} \mathrm{~B} . \mathrm{W})$. & & \\
$\quad$ Brain & $1.22 \pm 0.03$ & $1.16 \pm 0.02$ & $1.21 \pm 0.03$ & $1.19 \pm 0.02$ & $1.20 \pm 0.03$ \\
Heart & $0.47 \pm 0.02$ & $0.48 \pm 0.01$ & $0.48 \pm 0.02$ & $0.48 \pm 0.02$ & $0.50 \pm 0.02$ \\
Lung & $1.02 \pm 0.09$ & $0.96 \pm 0.06$ & $0.98 \pm 0.09$ & $1.10 \pm 0.08$ & $1.13 \pm 0.09$ \\
Liver & $3.97 \pm 0.07$ & $3.88 \pm 0.05$ & $4.00 \pm 0.09$ & $3.92 \pm 0.05$ & $4.02 \pm 0.08$ \\
Pancreas & $0.92 \pm 0.03$ & $0.84 \pm 0.03$ & $0.83 \pm 0.03$ & $0.88 \pm 0.04$ & $0.85 \pm 0.03$ \\
Spleen & $0.27 \pm 0.01$ & $0.33 \pm 0.01$ & $0.37 \pm 0.06$ & $0.32 \pm 0.02$ & $0.36 \pm 0.03$ \\
Kidney & $1.59 \pm 0.05$ & $1.53 \pm 0.04$ & $1.62 \pm 0.07$ & $1.66 \pm 0.05$ & $1.73 \pm 0.04$ \\
White adipose tissue & & & & & \\
$\quad$ Mesenteric & $0.96 \pm 0.07$ & $0.81 \pm 0.09$ & $0.85 \pm 0.08$ & $0.87 \pm 0.06$ & $0.88 \pm 0.12$ \\
$\quad$ Perinephric & $1.28 \pm 0.11$ & $1.33 \pm 0.18$ & $1.18 \pm 0.12$ & $1.23 \pm 0.10$ & $1.23 \pm 0.18$ \\
$\quad$ Epididymal & $2.27 \pm 0.14$ & $2.22 \pm 0.24$ & $1.88 \pm 0.22$ & $2.22 \pm 0.20$ & $1.98 \pm 0.25$ \\
$\quad$ Total & $4.59 \pm 0.29$ & $4.46 \pm 0.49$ & $3.91 \pm 0.38$ & $4.32 \pm 0.31$ & $4.09 \pm 0.47$ \\
\hline
\end{tabular}

Data are shown as mean $\pm \mathrm{SE}, \mathrm{n}=12$. Different superscript letters indicate significant differences ( $\left.{ }^{\mathrm{a}, \mathrm{b}} p<0.05\right)$. The $\mathrm{m} 60, \mathrm{~m} 75$, $\mathrm{m} 90$, and $\mathrm{m} 05$ groups were fed the 1960, 1975, 1990, and 2005 mimic oil diets, respectively, and the normal group was fed the AIN-93G powdered diet.

\subsection{Effects of mimic oil diets on serum biochemical pa- rameters}

There were no significant differences in serum TG levels among groups. Serum TC level was significantly lower in the mb05 group than the mb75 group. There were no significant differences among groups with respect to serum PL, glucose, or insulin levels (Table 12).

\section{DISCUSSION}

The present study investigated the effects of diets replicating the fatty acid composition and macronutrient ratio of Japanese diets at different times on visceral fat accumulation in growing mice. The results show the 1975 mimic oil-balanced diet suppressed visceral fat accumulation and adipocyte hypertrophy compared to the 1960, 1990, and 2005 mimic oil-balanced diets. To investigate the underlying mechanism, gene expressions in epididymal adipose tissue were analyzed by DNA microarray. The expression levels of 10 metabolism-related genes were significantly lower in the mice fed the 1975 mimic oil-balanced diet than those fed the other mimic oil-balanced diets; therefore, these genes were examined in detail. Genes involved in the inhibition of adipocyte hypertrophy included Acsbg1 and Ptgds. Acsbg1 synthesizes acyl-CoA from fatty acids, promotes TG synthesis, and induces adipocyte hypertrophy ${ }^{16)}$.
On the other hand, Ptgds synthesizes prostaglandin D2 from prostaglandin $\mathrm{H} 2$, which is a metabolite of arachidonic acid, and acts in the pathway to synthesize 15-deoxy prostaglandin J2 which is endogenous ligands on PPAR ${ }^{17,18}$. The activation of PPAR $\gamma$ by its endogenous ligand promotes adipocyte hypertrophy ${ }^{19)}$. In addition, although the gene expression ratio of the mb75 group was less than 2 compared to that of the other three groups, the major lipid metabolism-related genes were shown in Table 13. As a result, the modest difference was found in Fatty acid synthase (Fasn) and Uncoupling protein 1(Ucp1). The expression level of Fasn who promotes the lipid accumulation ${ }^{20)}$ was lowest in mb75 group. The expression level of Ucp 1 who promotes the energy consumption ${ }^{21)}$ was highest in mb75 group. In the present study, the 1975 mimic oil-balanced diet strongly inhibited the functions of these molecules, thus inhibiting adipocyte hypertrophy and visceral fat accumulation.

The observed anti-obesity effect of the 1975 mimic oilbalanced diet was considered to be due to differences in the intake levels of fatty acids or differences in fatty acid composition. Therefore, we investigated a mimic oil diet that replicated only the fatty acid composition of Japanese food. There were no significant differences in visceral fat mass or adipocyte size in mice fed the mimic oil diet. These results indicate the suppression of fat accumulation in white adipose tissue caused by the 1975 mimic oil-balanced 

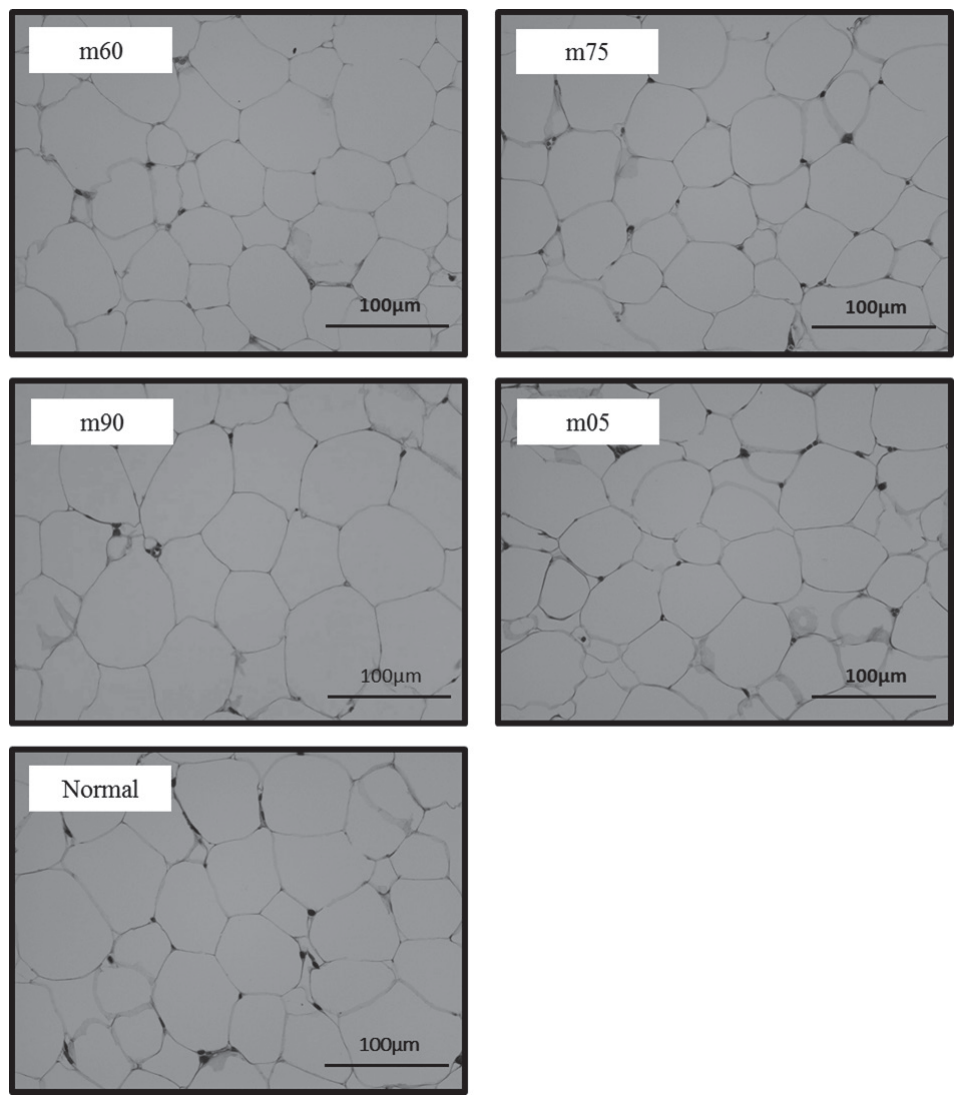

Fig. 2 Effects of the mimic oil diets on white adipose tissue in mice.

Epididymal adipose tissue sections from representative mice of each group (hematoxylin \& eosin, scale bar $=$ $100 \mu \mathrm{m})$. The $\mathrm{m} 60, \mathrm{~m} 75, \mathrm{~m} 90$, and $\mathrm{m} 05$ groups were fed the 1960, 1975, 1990, and 2005 mimic oil diets, respectively, and the normal group was fed the AIN-93G powdered diet.

Table 12 Biochemical parameters in serum in mice fed mimic oil diet.

\begin{tabular}{|c|c|c|c|c|c|c|}
\hline & & $\mathrm{m} 60$ & $\mathrm{~m} 75$ & $\mathrm{~m} 90$ & $\mathrm{~m} 05$ & Normal \\
\hline TG & $(\mathrm{mmol} / \mathrm{L})$ & $1.40 \pm 0.12$ & $1.45 \pm 0.13$ & $1.19 \pm 0.10$ & $1.16 \pm 0.09$ & $1.41 \pm 0.10$ \\
\hline $\mathrm{TC}$ & $(\mathrm{mmol} / \mathrm{L})$ & $2.70 \pm 0.19^{\mathrm{ab}}$ & $3.13 \pm 0.24^{\mathrm{b}}$ & $2.94 \pm 0.18^{\mathrm{ab}}$ & $2.37 \pm 0.09^{\mathrm{a}}$ & $2.64 \pm 0.19$ \\
\hline PL & $(\mathrm{mmol} / \mathrm{L})$ & $2.30 \pm 0.14$ & $2.63 \pm 0.16$ & $2.47 \pm 0.13$ & $2.27 \pm 0.13$ & $2.40 \pm 0.12$ \\
\hline Glucose & $(\mathrm{mmol} / \mathrm{L})$ & $4.15 \pm 0.16$ & $4.50 \pm 0.25$ & $4.03 \pm 0.21$ & $4.41 \pm 0.36$ & $4.63 \pm 0.31$ \\
\hline Insulin & $(\mathrm{pmol} / \mathrm{L})$ & $46.5 \pm 9.4$ & $43.1 \pm 8.2$ & $27.3 \pm 4.3$ & $28.2 \pm 1.9$ & $46.1 \pm 7.8$ \\
\hline
\end{tabular}

Data are shown as mean $\pm \mathrm{SE}, \mathrm{n}=12$. Different superscript letters indicate significant differences $\left.{ }^{\mathrm{a}}{ }^{\mathrm{a} b} p<0.05\right)$. The $\mathrm{m} 60, \mathrm{~m} 75, \mathrm{~m} 90$, and $\mathrm{m} 05$ groups were fed the 1960, 1975, 1990, and 2005 mimic oil diets, respectively, and the normal group was fed the AIN-93G powdered diet. TC, total cholesterol; TG, triacylglycerol; PL, phospholipid.

diet does not solely depend on its fatty acid composition. In addition, the amounts of lipids are reported to not significantly affect visceral fat ${ }^{7)}$. Thus, the results indicate the effect of 1975 mimic oil-balanced diet depends on both the composition and amounts of fatty acids.

What of the 1975 mimic oil-balanced diet affected the suppression of fat accumulation was discussed. The tran- scription of Ptgds, whose expression was decreased in the mice fed the 1975 mimic oil-balanced diet, is controlled by Srebp- $1 c^{22)}$. Srebp-1c is activated by saturated fatty acids and inhibited by polyunsaturated fatty acids, particularly $\mathrm{EPA}$ and $\mathrm{DHA}^{23)}$. Therefore, fatty acid intake levels in the two experiments of mimic oil-balanced diet and mimic oil diet were compared. The intake levels of saturated fatty 
Table 13 Lipid metabolism-related gene.

\begin{tabular}{llrrrl}
\hline \multirow{2}{*}{ Gene Accession } & \multirow{2}{*}{ Gene Symbol } & \multicolumn{3}{c}{ Expression ratio (vs mb60) } & \multirow{2}{*}{ Pathway } \\
\cline { 3 - 4 } & & $\mathrm{mb75}$ & $\mathrm{mb90}$ & $\mathrm{mb05}$ & \\
\hline NM_007643 & Cd36 & -0.05 & 0.02 & -0.08 & \multirow{2}{*}{ transport } \\
NM_008509 & Lpl & 0.03 & 0.12 & -0.05 & \\
\hline NM_007988 & Fasn & -0.52 & -0.25 & -0.23 & \\
NM_008062 & G6pdh & 0.06 & 0.14 & 0.04 & \\
NM_001198933 & Mel & 0.01 & 0.13 & 0.17 & \\
NM_145494 & Me2 & -0.10 & -0.05 & -0.07 & lipogenesis \\
NM_181407 & Me3 & 0.08 & 0.30 & 0.31 & \\
NM_011146 & Pparg & 0.08 & -0.13 & -0.33 & \\
NM_011480 & Srebp-1c & 0.10 & 0.08 & 0.33 & \\
\hline NM_010719 & Hsl & 0.12 & 0.06 & -0.03 & \multirow{2}{*}{ lipolysis } \\
NM_011145 & Ppard & 0.01 & 0.05 & -0.13 & \\
\hline NM_009463 & Ucpl & 0.55 & -0.62 & -1.13 & energy expenditure \\
\hline
\end{tabular}

The bottom was expressed as 2 in logarithm. The lipid metabolism-related gene expression ratio of $\mathrm{mb} 75$ group was less than 2 times compared to the other three groups in epididymal adipose tissue. The mb60, mb75, mb90, and mb05 groups were fed the 1960, 1975, 1990, and 2005 mimic oil-balanced diets, respectively. Cd36, Cluster of differentiation 36; Fasn, Fatty acid synthase; G6pdh, Glucose-6-phosphate dehydrogenase; Hsl, hormonsensitive lipase; $L p l$, lipoprotein lipase; $M e 1$, Malic enzyme 1; Me2, Malic enzyme 2; Me3, Malic enzyme 3; Ppard, Peroxisome proliferator-activated receptor $\delta$; Pparg, Peroxisome proliferator-activated receptor $\gamma ;$ Srebp$1 c$, Sterol regulatory element- binding protein-1c; Ucpl, Uncoupling protein 1.

acid in the mice fed the 1960, 1975, 1990, and 2005 mimic oil-balanced diets were $49.1 \pm 2.4,79.0 \pm 3.4,120 \pm 6.0$, and $125 \pm 7.0 \mathrm{mg} /$ day, respectively; the intake levels of EPA + DHA were $4.21 \pm 0.21,6.80 \pm 0.29,6.53 \pm 0.32$, and $10.9 \pm$ $0.6 \mathrm{mg} /$ day, respectively. Whereas the intake levels of EPA and DHA did not change substantially, those of saturated fatty acids increased significantly over time. Thus, the greater visceral fat accumulation in the 1990 and 2005 mimic oil-balanced diet groups is likely due to higher saturated fatty acid intake than that in the 1975 mimic oil-balanced diet group. Furthermore, visceral fat accumulation in the 1960 mimic oil-balanced diet group is considered to be due to high carbohydrate intake. Low-fat/high-carbohydrate diets are reported to enhance lipid synthesis ${ }^{24)}$. Therefore, a similar phenomenon likely occurred in the rats fed the 1960 mimic oil-balanced diet. In addition, the stepwise multiple regression analysis was performed by using the total white adipose tissue weights as the objective variable and the fatty acid composition as the explanatory variable. The positive correlation was observed between the saturated fatty acids, especially 14:0 and 18:0, and total white adipose tissue weights. In addition, the negative correlation was observed between linoleic acid $(18: 2 \mathrm{n}-6)$ and total white adipose tissue weights. It was suggested that white adipose tissue weights are affected of the saturated fatty acid. As shown Table 9, the rate of linoleic acid was large and the rate of arachidonic acid (20:4 n-6) was lowest in mb75 group, so it was considered that the $\Delta 6$-desaturase activity in mb75 group is low ${ }^{14)}$. Hence, it was suggested that the generation of endogenous ligands on PPAR $\gamma$ is less ${ }^{19,20)}$. Moreover, these changes in fatty acid composition was also observed in serum and liver.

On the other hand, in the mimic oil diet experiment, mean saturated fatty acid intake was $77.0 \pm 3.3,71.8 \pm 1.7$, $83.6 \pm 4.4$, and $75.6 \pm 2.4 \mathrm{mg} /$ day in the in the mice fed the 1960, 1975, 1990, and 2005 mimic oil diets, respectively; $\mathrm{EPA}+\mathrm{DHA}$ intake was $6.60 \pm 0.28,6.18 \pm 0.14,4.56 \pm 0.24$, and $6.62 \pm 0.21 \mathrm{mg} /$ day, respectively. Because there were no significant differences in intake levels of saturated fatty acids and EPA + DHA, the diets were considered to have no effect on visceral fat mass.

The S:M:P ratios of the Japanese diets were similar. Also, the $\omega 6: \omega 3$ ratio was not lowest in the 1975 diet; nevertheless, intake of the 1975 mimic oil-balanced diet suppressed fat accumulation. This suggests there are better indices of assessing the effect of lipid composition on health maintenance than the S:M:P and $\omega 6: \omega 3$ ratios that are currently published. In the future, we will analyze the composition and quantities of fatty acids in the 1975 diet in greater detail in order to clarify way to take fat effectively to the health maintenance. 


\section{CONCLUSION}

The present study shows that both the quality and quantity of fatty acids are important for the previously reported anti-obesity effects of the 1975 Japanese diet. However, this diet does not improve sugar metabolism or the inhibitory effect of liver lipid accumulation. Thus, the results suggest this diet affects components other than fatty acids, including unsaponifiables, proteins, carbohydrates, minerals, vitamins, etc. Accordingly, we are planning to investigate components of this diet other than fatty acids in detail.

\section{ACKNOWLEDGMENT}

This study was supported by Integration research for agriculture and interdisciplinary fields for Bio-oriented Technology Research Advancement Institution(BRAIN), Japan. There are no conflicts of interest.

\section{SUPPORTING INFORMATION}

This material is available free of charge via the Internet at http://dx.doi.org/jos.65.10.5650/jos.ess.15150

\section{References}

1) Tsuduki, T; Takeshika, N; Nakamura, Y; Nakagawa, K; Igarashi, M; Miyazawa, T. DNA Microarray Analysis of Rat Liver after Ingestion of Japanese and American Food. J. Jpn. Soc. Nutr. Food Sci. 61, 255-264 (2008).

2) Jelinek, D.; Castillo, J. J.; Arora, S. L.; Richardson, L. M.; Garver, W.S. A high-fat diet supplemented with fish oil improves metabolic features associated with type 2 diabetes. Nutr. 29, 1159-1165 (2013).

3) Nakagawa, K; Ninomiya, M; Okubo, T; Aoi, N; Juneja, L. R.; Kim, K; Yamanaka, K; Miyazawa, T. Tea catechin supplementation increases antioxidant capacity and prevents phospholipid hydroperoxidation in plasma of humans. J. Agric. Food Chem. 47, 3967-3973(1999).

4) Anderson, J. W.; Johnstone, B. M.; Cook-Newell, M. E. Meta-Analysis of the Effects of Soy Protein Intake on Serum Lipids. N. Engl. J. Med. 333, 276-282(1995).

5) Ministry of Agriculture, Forestry and Fisheries. Food Supply and Demand Table(2014).

URL http://www.maff.go.jp/j/tokei/kouhyou/zyukyu/index.html. Accessed 15.03.31.

6) Honma, T; Kitano, Y; Kijima, R; Jibu, Y; Kawakami, Y; Tsuduki, T; Nakagawa, K; Miyazawa, T. Comparison of the Health Benefits of Different Eras of Japanese Foods: Lipid and Carbohydrate Metabolism Focused
Research. J. Jpn. Soc. Food Sci. Technol. 60, 541553 (2013).

7) Kitano, Y; Honma, T; Hatakeyama, Y; Jibu, Y; Kawakami, Y; Tsuduki, T; Nakagawa, K; Miyazawa, T;. Effects of Historical Differences in Components of the Japanese Diet on the Risk of Obesity in Mice. Jpn. Soc. Nutr. Food Sci. 67, 73-85(2014).

8) Bligh, E. G.; Dyer, W. J. A rapid method of total lipid extraction and purification. J. Physiol. Biochem. 37, 911-917 (1959).

9) Tsuzuki, T; Kawakami, Y; Abe, R; Nakagawa, K; Koba, K; Imamura, J; Iwata, T; Ikeda, I; Miyazawa, T. Conjugated linolenic acid is slowly absorbed in rat intestine, but quickly converted to conjugated linoleic acid. $J$. Nutr. 136, 2153-2159(2006).

10) Tsuzuki, T; Tokuyama, Y; Igarashi, M; Nakagawa, K; Ohsaki, Y; Komai, M; Miyazawa, T. $\alpha$-Eleostearic acid (9Z11E13E-18:3) is quickly converted to conjugated linoleic acid(9Z11E-18:2) in rats. J. Nutr. 134, 26342639 (2004).

11) Tsuduki, T; Kikuchi, I; Kimura, T; Nakagawa, K; Miyazawa, T. Intake of mulberry 1-deoxynojirimycin prevents diet-induced obesity through increases in adiponectin in mice. Food Chem. 139, 16-23 (2013).

12) Takasaki, M; Honma, T; Yanaka, M; Sato, K; Shinohara, N; Ito, J; Tanaka, Y; Tsuduki, T; Ikeda, I. Continuous intake of a high-fat diet beyond one generation promotes lipid accumulation in liver and white adipose tissue of female mice. J. Nutr. Biochem. 23, 640-645 (2012).

13) Tsuduki, T; Kitano, Y; Honma, T; Kijima, R; Ikeda, I. High dietary fat intake during lactation promotes development of diet-induced obesity in male offspring of mice. J. Nutr. Sci. Vitaminol. 59, 384-392(2013).

14) Shinohara, N; Ito, J; Tsuduki, T; Honma, T; Kijima, R; Sugawara, S; Arai, T; Yamasaki, M; Ikezaki, A; Yokoyama, M; Nishiyama, K; Nakagawa, K; Miyazawa, T; Ikeda, I. Jacaric acid, a linolenic acid isomer with a conjugated triene system, reduces stearoyl-CoA desaturase expression in liver of mice. J. Oleo Sci. 61, 433-441 (2012).

15) Rouser, G; Fleischer, S; Yamamoto, A. Two dimensional then layer chromatographic separation of polar lipids and determination of phospholipids by phosphorus analysis of spots. Lipids 5, 494-496 (1970).

16) Mashek, D. G.; Li, L. O.; Coleman, R. A. Long-chain acyl-CoA synthetases and fatty acid channeling. Future Lipid. 2, 465-476 (2007).

17) Lu, S; Nishimura, K; Hossain, M. A.; Jisaka, M; Nagaya, $\mathrm{T}$; Yokota, K. Regulation and Role of Arachidonate Cascade During Changes in Life Cycle of Adipocytes. Biochem. Biotech. 118, 133-153(2004).

18) Powell, W. S. 15-deoxy- $\Delta 12,14$-PGJ2: endogenous PPAR $\gamma$ ligand or minor eicosanoid degradation prod- 
uct? J. Clin. Invest. 112, 828-830 (2003).

19) Fujimori, K. Prostaglandins as PPAR $\gamma$ Modulators in Adipogenesis. PPAR Research, Article ID 527607, 8 pages (2012).

20) Lodhi, I. J.; Yin, L.; Jensen-Urstad, A. P. L.; Funai, K; Coleman, T.; Baird, J. H.; El Ramahi, M. K.; Razani, B.; Song, H.; Fu-Hsu, F.; Turk, J.; Semenkovich, C.F. Inhibiting Adipose Tissue Lipogenesis Reprograms Thermogenesis and PPAR $\gamma$ Activation to Decrease Diet-Induced Obesity. Cell Met. 16, 189-201 (2012).

21) Nedergaard, J.; Ricquier, D.; Kozak, L. P. Uncoupling proteins: current status and therapeutic prospects. EMBO report 6, 917-921 (2005).

22) Fujimori, K; Aritake, K; Urade, Y; A Novel Pathway to Enhance Adipocyte Differentiation of 3T3-L1 Cells by
Up-regulation of Lipocalin-type Prostaglandin D Synthase Mediated by Liver X Receptor-activated Sterol Regulatory Element-binding Protein-1c. J. Biol. Chem. 282, 18458-18466(2007).

23) Shimano, H. SREBP-1c and TFE3, energy transcription factors that regulate hepatic insulin signaling. $J$. Mol. Med. 85, 437-444(2007).

24) Shimano, H; Yahagi, N; Amemiya-Kudo, M; Hasty, A. H.; Osuga, J; Tamura, Y; Shionoiri, F; Iizuka, Y; Ohashi, K; Harada, K; Gotoda, T; Ishibashi, S; Yamada, N. Sterol Regulatory Element-binding Protein-1 as a Key Transcription Factor for Nutritional Induction of Lipogenic Enzyme Genes. J. Biol. Chem. 274, 35832-35839 (1999). 